\title{
Composition and Properties of Coolant Concentrate Obtained By a Dynamic Membrane
}

\author{
Dinar Dilshatovich Fazullin ${ }^{1}$, Gennady Vitalievich Mavrin², Diana Aleksandrovna Yarovikova ${ }^{3}$ \\ ${ }^{1}$ Candidate of Technical Sciences, Associate Professor of the Department of Chemistry and Ecology, Civil Engineering \\ Department, Naberezhnye Chelny Institute of KFU, Kazan Federal University, Russia. Id scopus 56091448500 , \\ ORCID 0000-0002-5017-2535, \\ ${ }^{2}$ Candidate of Chemical Sciences., Head of the Department of Chemistry and Ecology, Engineering and Construction \\ Department, Naberezhnye Chelny Institute KFU, Kazan Federal University, Russia. Id scopus 56091349400,
}

ORCID 0000-0003-0276-4365,

${ }^{3}$ Certified bachelor (specialist) in the field of training 03/20/01 "Technosphere safety" of the Naberezhnye Chelny Institute of the Kazan (Volga Region) Federal University, Kazan Federal University, Russia.

ORCID 0000-0002-6720-8928,

\begin{abstract}
Spent cutting fluids (coolant) are formed from the activity of metal processing, as a result of contamination and biodefeat of the emulsion. For disposal of spent coolant, vacuum distillation and reagent decomposition methods are used, but membrane separation methods are the most effective and environmentally friendly. In the process of separation of spent coolant by membrane methods, a concentrate is formed consisting of petroleum products (NP), fats, surfactants. Using the method of high-performance liquid chromatography using a light scattering detector, the content of fatty acids in the concentrate of fresh and spent cutting fluid obtained from a $3 \%$ emulsion using a dynamic membrane with a polystyrene surface layer was studied. The calibration dependence of the fatty acid content from $2 \mathrm{mg} / \mathrm{dm} 3$ to $8 \mathrm{mg} / \mathrm{dm} 3$ is established. It has been shown that fatty acids such as palmitic and stearic, along with petroleum products, have a negative effect on aquatic ecosystems. The experimental conditions for the quantitative analysis of fatty acids, in particular, the parameters of calibration graphs, are determined. It was found that the concentration of stearic acid in spent coolant exceeds the maximum permissible concentration for fishery waters by 14,000 times. Due to the high content of oil products, the concentrate obtained can be used as heating oil or an inhibitory additive to protect pipelines from the corrosive effects of produced water.
\end{abstract}

Keywords: Cutting Fluid, Fats, Stearic Acid, Petroleum Products, Ultrafiltration.

\section{INTRODUCTION}

Currently, much attention is paid to the cleaning and disposal of used cutting fluid (coolant) in the machine-building industry. The need for disposal is associated with the goal of preventing the release of toxic substances into the environment, as well as in order to avoid the possibility of harmful effects of production and consumption waste on human health with the subsequent preservation of the natural environment $[1,2]$. As a result of exposure to coolant at high temperatures, impurities, and the multiplication of microorganisms, the emulsion loses its properties: the hydrogen index, light, odor, density decreases, which requires replacing the spent emulsion with fresh coolant. Subsequently, the emulsion begins, exfoliates into an aqueous and an oil phase. There is a need for disposal of spent coolant, which is an urgent problem for the machine-building complex, where the volume of formation of spent coolant is $10-60 \mathrm{~m}^{3} /$ day [3-5].

The main component of oil coolants are oils: mineral (up to $70 \ldots 90 \%$ ), industrial. As additional components, technical vegetable oils and small amounts of technical animal fats are used, which are mainly used to produce oleic acid. Emulsions of mineral oils can be used with various anti-seize, anti-corrosion, detergents, antibacterial and other additives [6].

Fats are widely used as complex multifunctional additives to mineral oils [7]. Fats in the coolant are also used as antifriction, anti-seize, anti-wear additives. Antifriction additives in oil coolants are contained in a concentration of 5 to $25 \%$. They are mainly composed of organic or polymeric unsaturated fatty acids, their esters, vegetable oils and fats. Anti-seize additives are substances containing sulfur, chlorine, phosphorus. The most common are sulfides, polysulfides, sulfurized fats and chlorinated paraffin. Their concentration depends on the purpose and application of the coolant and varies from 0.5 to $20 \%$. Antiwear additives are polymeric fatty acids, dialkyl phosphates or sulphurous fats. As antifoam additives, dimethylselicone polymers are used.

To prevent corrosion on parts of equipment, as well as on workpieces, corrosion inhibitors are added to oil coolants, which may include unsaturated fatty acids, as well as disulfides and aminophosphates.

When analyzing complex mixtures of fatty acids, high performance chromatography (HPLC) is widely used. This method is a column chromatography method in which a liquid moving through a chromatographic column filled with a stationary phase (sorbent) is the mobile phase. This method allows for a minimum cost of sample preparation and the 
absence of the strict need for substances to conduct a reliable analysis of the content of fatty acids in the samples.

Currently, the problem of pollution of the machine-building complex with industrial wastewater containing various components, including fatty acids, has increased. The purification of fat-containing wastewater is difficult due to the multiphase composition of fats - fats can be in water in the form of a surface film, emulsion and solution. Fatty acids in various phase states require different processing methods $[8,9]$.

\section{METHODS}

The spent 3\% water-oil coolant was subjected to ultrafiltration by concentration. During the separation of the emulsion, a pressure of $0.7 \mathrm{MPa}$ was applied; the temperature of the liquid was $-25^{\circ} \mathrm{C}$.

Separation experiments were carried out on a laboratory membrane separation unit, the scheme of which is shown in Figure 1.

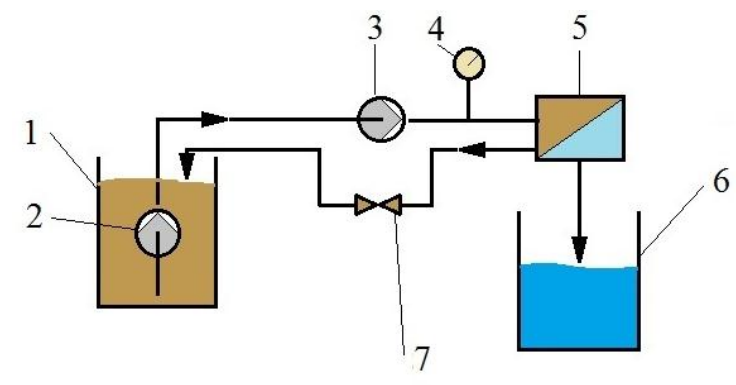

Figure 1. Laboratory ultrafiltration unit: (1 - container with spent coolant, 2 - submersible pump, 3 - high pressure pump, 4 - pressure gauge, 5 - ultrafiltration module, 6 - container for collecting filtrate, 7 - concentrate flow restrictor)

The initial emulsion was supplied from the tank (1) to the ultrafiltration module (5). Under the pressure generated by the pump (3) and recorded by a manometer (4), the emulsion was divided into concentrate and permeate. The latter was collected in a receiving tank (6), the concentrate was returned to the tank with the original emulsion. Pressure is regulated by a flow restrictor. In the process, there is a gradual concentration of impurities to the maximum possible values. The filtrate is used to obtain a new portion of coolant, or is discharged into the sewage system, and the coolant concentrate must be disposed of or recycled. Therefore, the composition and properties of the spent water-oil coolant concentrate were further investigated. The composition of the spent coolant concentrate established the content of oil products, fatty acids, surfactants, and suspended solids.

The fatty acid content was analyzed by high performance liquid chromatography on a Stayer chromatographic system with a low temperature light scattering detector 80 , on a Synergi Fusion-RP analytical column.
The light scattering detector low temperature evaporative model 80 is a universal device that allows to detect any nonvolatile analyzed component. The response of the detector does not depend on the absorption or emission of light by the analyte molecule or on the optical purity of the solvents that are components of the mobile phase. The detection process consists of three stages: the conversion of the eluent to a fine aerosol, its subsequent evaporation, and the detection of light scattered by the components of the sample. At the initial stage, the eluate from the chromatographic column turns into a fine aerosol in a gas stream. The aerosol enters the evaporation tube, the volatile components of the aerosol evaporate, and the particles of non-volatile components of the sample enter the detection device. By the degree of scattering by light particles, one can judge the concentration of the analyzed components of the sample.

Chromatographic separation and detection conditions:

- separation mode - isocratic;

- mobile phase - acetonitrile - water $-\mathrm{CH} 3 \mathrm{COOH}$ solution,

(110: $12: 3$ vol. $\mathrm{H})$;

- separation column: "Synergi Fusion-RP" 4 microns, 250x4.6 $\mathrm{mm}$;

- Protective column: "Fusion-RP”, 4x3.0 mm;

- flow rate $-0.9 \mathrm{~cm}^{3} / \mathrm{min}$;

- temperature $-+20^{\circ} \mathrm{C}$;

- the volume of the loop dispenser - $10 \mu \mathrm{l}$;

- detection - by light scattering, temperature of the evaporation tube $-+40{ }^{\circ} \mathrm{C}$; the gas pressure at the detector inlet is 3.0 bar, the output signal gain is 1.0 [10].

The preparation of samples of the emulsion concentrate for measuring the mass content of fatty acids by HPLC involves the following steps:

- alkaline hydrolysis of ester bonds of triglycerides of the analyzed product with the release of fatty acids;

- selection of an aliquot of hydrolyzate;

- sample preparation for input into the chromatograph.

The method of IR spectrometry was used to study the oil content in the emulsion concentrate using a KN-3 concentrator. The method for measuring the mass concentration of oil products is based on the dependence of the intensity of absorption of $\mathrm{CH}$ bonds in the infrared region of the spectrum $(2930 \pm 70) \mathrm{cm}^{-1}$ on the mass concentration of oil products in the eluate.

Investigations of the particle size distribution of the studied emulsions were carried out using a particle size analyzer and $\zeta$-potential of the Nano Brook Omni brand. Measurements based on the principles of dynamic light scattering (DLS) for determining particle sizes and electrophoretic light scattering (ELS) for the zeta potential usually take only 1-2 minutes. The instrument also uses the phase analysis method (PALS) for samples with low mobility. 
International Journal of Engineering Research and Technology. ISSN 0974-3154, Volume 13, Number 11 (2020), pp. 3524-3529

(C) International Research Publication House. https://dx.doi.org/10.37624/IJERT/13.11.2020.3524-3529

The potentiometric determination of the hydrogen index of water was carried out using an Anion 4100 brand ionomer / $\mathrm{pH}$ meter. The $\mathrm{pH}$ meter was adjusted using three buffer solutions with $\mathrm{pH}=4.01,6.86,9.18$, and 12.3 prepared from standard titers.

The content of nonionic surface active substances (surfactants) was determined by the photometric method using a UNICO 2800 spectrophotometer.

Optical photographs of the spent coolant concentrate were made using a light microscope with an integrated digital camera at a magnification of 1000 times.

\section{RESULTS AND DISCUSSION}

A concentrate of a $3 \%$ coolant emulsion was obtained by separating the spent coolant of the "Isanol VPS-2" brand with a dynamic ultrafiltration membrane with a surface layer of cellulose acetate particles. The experiment was carried out on a laboratory membrane installation. The parameters of the membrane separation of the spent emulsion are presented in Figure 2. The separation of the emulsion was carried out with a PTFEg-PSd dynamic membrane $[11,12]$ at a working pressure of $0.6 \mathrm{MPa}$, the concentration of oil products in the emulsion was $33 \mathrm{~g} / \mathrm{dm}^{3}$

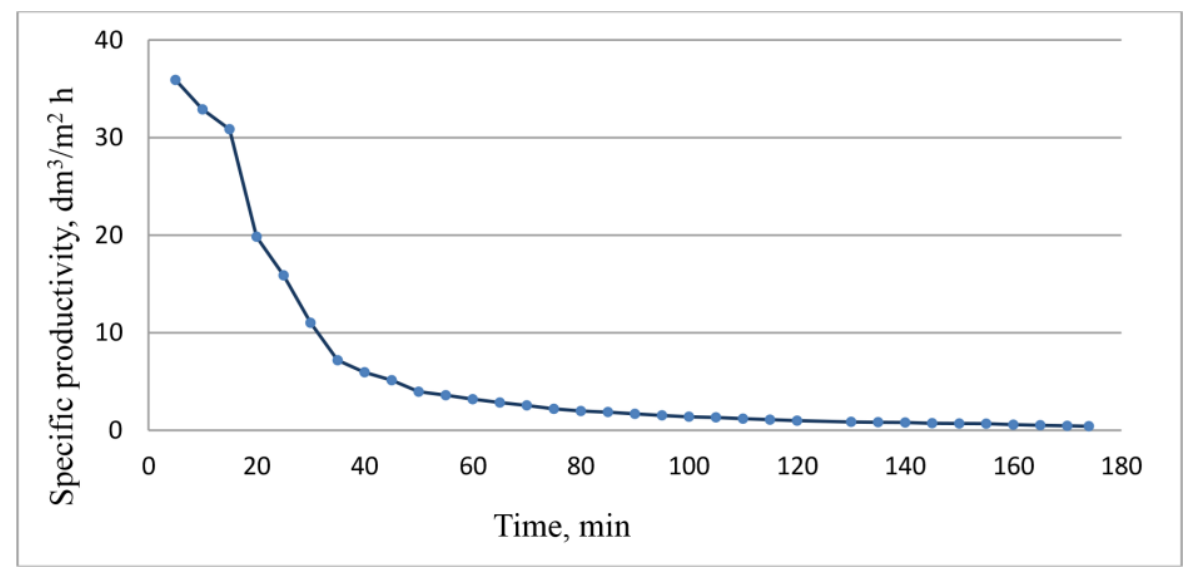

Figure 2. Dependence of the specific productivity of the PTFEg-PSd membrane on the separation time

According to Figure 2, during the separation of spent coolant using a dynamic PTFEg-PSd membrane, the first 40 minutes of operation show an intensive decrease in the specific productivity of the membrane from 36 to $8 \mathrm{dm}^{3} / \mathrm{m}^{2} \mathrm{~h}$, after which the specific productivity continues to gradually decrease. Therefore, to maintain productivity at the level of $10 \mathrm{dm}^{3} / \mathrm{m}^{2} \mathrm{~h}$, it is necessary to wash the membrane after 30-40 minutes of operation. As a result of the separation of $5 \mathrm{dm}^{3}$ of spent coolant, $4.4 \mathrm{dm}^{3}$ of filtrate and $0.6 \mathrm{dm} 3$ of concentrate were formed.

In order to find possible directions for using the concentrate, we determined the component composition and properties of the latter.

The properties of the spent coolant concentrate are presented in table 1.

Table 1. Properties of spent coolant concentrate

\begin{tabular}{|c|c|}
\hline Indicator & Measurement Results \\
\hline $\mathrm{pH}$ units $\mathrm{pH}$ & 8.2 \\
\hline $\mathrm{UEP}, \mu \mathrm{S} / \mathrm{cm}$ & 1130 \\
\hline Total mineralization, $\mathrm{mg} / \mathrm{dm} 3$ & 0.910 \\
\hline Density $\rho, \mathrm{kg} / \mathrm{m} 3$ & $112-165 ; 331-456$ \\
\hline Particle sizes, $\mathrm{nm}$ & 4.3 \\
\hline$\xi$ potential, $\mathrm{mV}$ & \\
\hline
\end{tabular}

The emulsion concentrate has a density of 0.910 close to the density of industrial grade I-20 oil of 0.890 . The hydrogen indicator of the concentrate spent coolant slightly alkaline 8.2 units $\mathrm{pH}$, in a fresh emulsion should correspond to 9-10.5 units. $\mathrm{pH}$ The particle size distribution of the spent emulsion concentrate is shown in Figure 3. 


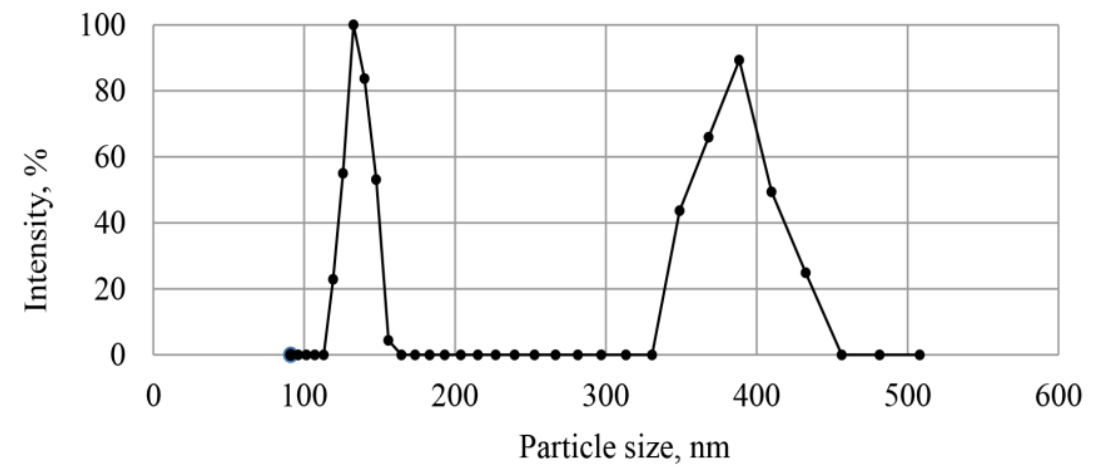

Figure 3. Graph of the particle size distribution of the dispersed phase of the spent emulsion concentrate

According to Figure 3 and Table 1, the spent coolant concentrate is a polydisperse system, the particle sizes of which are distributed in the range from 112-165 and 331-456 nm. The emulsion is not stable, the absolute value of the $\xi$ potential is $4.3 \mathrm{mV}$.

Next, we conducted a study of the component composition of the spent coolant concentrate. The study of the mass content of fatty acids in the concentrate spent coolant brand "Isanol VPS-2" was carried out by HPLC. Two types of fatty acids, palmitic and stearic, were identified in the spent coolant concentrate. The release time of palmitic acid in the chromatogram was set at 12 minutes, and stearic acid in 18 minutes. The peak intensity was at a concentration of fatty acids of $6 \mathrm{mg} / \mathrm{dm}^{3}$ from 90 to $110 \mathrm{mV}$.

The component composition of the spent coolant concentrate is presented in table 2. The content of petroleum products, solids, fatty acids and surfactants was determined as a component of the coolant concentrate.

Table 2. The component composition of the concentrate spent cutting fluid "Isanol VPS-2".

\begin{tabular}{|c|c|c|}
\hline Ingredients & $\begin{array}{l}\text { Concentration, } \mathrm{mg} / \mathrm{kg} \\
(\mathrm{P}=0.95, \mathrm{n}=2)\end{array}$ & Content, $\%(\mathrm{P}=0.95, \mathrm{n}=2)$ \\
\hline Oil products & 585500 & 58,55 \\
\hline Mechanical impurities & 3250 & 0,33 \\
\hline Stearic acid & 30234 & 3,02 \\
\hline Palmitic acid & 161456 & 16,14 \\
\hline Nonionic surfactants & 147312 & 14,73 \\
\hline Water & 5433 & 5,43 \\
\hline Total & 1000000 & 100,00 \\
\hline
\end{tabular}

From table 2 it follows that the composition of the spent emulsion concentrate has a high concentration of petroleum products of more than $58 \%$, palmitic acid of more than $16 \%$ and nonionic surfactants of more than $14 \%$. The water content in the concentrate is $5.4 \%$, also in the concentrate there are mechanical impurities established by the gravimetric method, equal to $3 \%$.

The main component in the composition of the oil-water emulsion is industrial oil. Technical requirements, acceptance rules, test methods, transportation and storage conditions, as well as industrial quality control methods for industrial oil I 20A are strictly regulated by GOST 2079988. The most common area of application of I-20A industrial oil is its operation in various hydraulic systems of industrial equipment, construction machines, metal cutting machines, automatic lines, press lines, for lubricating lightloaded gears, medium-loaded gears, rolling and sliding guides of machines and other mechanisms for which specialty lubricants are not required. The parameters of the coolant concentrate do not comply with GOST for the content of water and solids.

Coolant concentrate Isanol VPS-2 is a flammable liquid. with a self-ignition temperature of $320^{\circ} \mathrm{C}$. To use the spent coolant concentrate as heating oil, we consider the conditions in accordance with GOST 10585-99, which establishes requirements for the composition and properties of heating and naval fuels. According to the requirements of GOST, the spent coolant concentrate is close to fuel oil 100, type IV. So, the flash point of heating oil 100 in an open crucible is $110^{\circ} \mathrm{C}$, and for a coolant concentrate not more 
than $140{ }^{\circ} \mathrm{C}$. The density of fuel oil is not standardized, the mass concentration of water and mechanical impurities should be no more than $1 \%$, the water content in the coolant concentrate does not comply with this GOST.

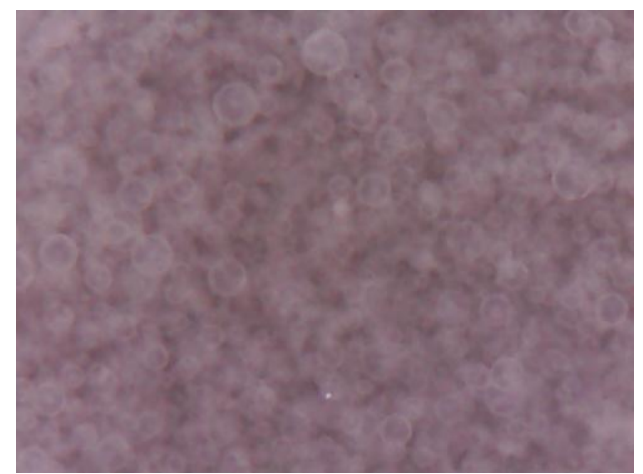

Figure 4. Optical photo of spent coolant concentrate $(1000 \mathrm{x}$ magnification).

Figure 4 shows the presence in the concentrate of spent coolant many oil particles that are interconnected.

\section{SUMMARY}

The spent 3\% water-oil coolant was subjected to concentration by ultrafiltration using a dynamic membrane. The average specific membrane productivity was $10 \mathrm{dm}^{3} /$ $\mathrm{m}^{2} \mathrm{~h}$, at a pressure of $0.6 \mathrm{MPa}$ and under the condition of washing the membrane every 30-40 minutes of operation.

As a result of the separation of $5 \mathrm{dm}^{3}$ of spent coolant, 4.2 $\mathrm{dm}^{3}$ of filtrate and $0.6 \mathrm{dm}^{3}$ of concentrate were formed. The concentration coefficient was 8.3 times.

The properties of the spent coolant concentrate were studied: density, hydrogen index, mineralization. The particle sizes of the dispersed phase and the value of the $\zeta$-potential of the emulsion are established.

Using the methods of gravimetry, photometry, IR spectrometry and high performance liquid chromatography, the component composition was established. The main components of the spent coolant concentrate in order to reduce the mass content are: petroleum products, fatty acids, nonionic surfactants, water and solids.

By properties and component composition, the spent coolant concentrate is close to fuel oil of grade 100, type IV.

\section{CONCLUSIONS}

Thus, as a result of the studies, the possibility of using a concentrate formed as a result of membrane separation of the spent emulsion as a heating oil after removing water has been shown. The studies determined the composition and properties of the spent coolant concentrate and the parameters of the membrane concentration of the emulsion.

\section{ACKNOWLEDGEMENTS}

The work is performed according to the Russian Government Program of Competitive Growth of Kazan Federal University. This work was supported by a grant from the President of the Russian Federation for state support of young Russian scientists - candidates of sciences (MK-1107.2019.8).

\section{REFERENCES}

[1] Makarova IA, Faizov RR, Buzaeva MV. Utilization of a nanomodified dispersion of cutting fluid using natural sorbents. Bulletin of the South Ural State University. Series: Chemistry. 2017;2: 5-12.

[2] Fazullin DD, Mavrin GV, Shaikhiev IG. Investigation of the properties and composition of a concentrate of spent Inkam-1 emulsion as a corrosion inhibitor. Petroleum Chemistry. 2017 Aug 1;57(8):728-33.

[3] Gorchakov EV, Bagamaev BM, Fedota NV, Orobets VA. Fundamentals of Biological Chemistry: A Training Manual. St. Petersburg: Lan Publishing House. 2019;208 pp.

[4] Fazullin DD, Mavrin GV, Shaikhiev IG, Nizameev IR. Ultrafiltration of oil-in-water emulsions with a dynamic nylon-polystyrene membrane. Petroleum Chemistry. 2018 Feb 1;58(2):145-51.

[5] Fazullin DD, Mavrin GV. Separation of Water-Oil Emulsions Using Composite Membranes with a Cellulose Acetate Surface Layer. Chemical and Petroleum Engineering. 2019 Nov 1;55(7-8):649-56.

[6] Mechanism of action and composition of the coolant [Electronic resource]. - Access mode: https://studopedia.su/20_91165_mehanizm-deystviyai-sostav-sozh.html (Date of access 12.01.2020)

[7] Schegolev AE, Yakovlev IP, Organic chemistry. For pharmaceutical and chemical-biological specialties of universities: Textbook. St. Petersburg: Publishing House" Lan ". 2017; c. 544.

[8] Water purification from fats [Electronic resource]: Access mode: https:/www.vo-da.ru/articles/ochistkavody-ot-jirov/fiziko-himicheskie metody-ochistki (Date of treatment 01.24.2020)

[9] Lobo A, Cambiella A, Benito JM, Pazos C, Coca J. The membrane technique of nanofiltration (NF) was used to carry out partial demineralization of whey and milk ultrafiltration permeate (MUP). Journal of Membrane Science. 2006;278(1-2): 328.

[10] FR.1.31.2008.04633, Methodology for measuring the mass fraction of fatty acids in animal and vegetable fats and oils, margarines, cooking fats, confectionery and baking industries using high performance chromatography, 2008.

[11] Zhang G, Jia X, Xing J, Shen S, Zhou X, Yang J, Guo Y, Bai R. A Facile and Fast Approach To Coat 
International Journal of Engineering Research and Technology. ISSN 0974-3154, Volume 13, Number 11 (2020), pp. 3524-3529

(C) International Research Publication House. https://dx.doi.org/10.37624/IJERT/13.11.2020.3524-3529

Various Substrates with Poly (styrene-co-maleic anhydride) and Polyethyleneimine for Oil/Water Separation. Industrial \& Engineering Chemistry Research. 2019 Sep 18;58(42):19475-85.

[12] Fazullin DD, Mavrin GV. ULTRAFILTRATION OF MODEL «OIL-IN-WATER» EMULSIONS WITH POLYSULFONAMIDE. TURKISH ONLINE JOURNAL OF DESIGN ART AND COMMUNICATION. 2017 Dec 1;7:1643-51. 